\title{
SS 316L/HA composite via powder injection moulding: Mechanical and physical properties
}

\author{
N. A. Johari' ${ }^{1}$ F. R. M. Romlay ${ }^{2}$, W. S. W. Harun ${ }^{3 *}$ \\ ${ }^{1}$ Institute of Postgraduate Studies, Universiti Malaysia Pahang, Lebuhraya Tun Razak, \\ 26300 Gambang, Kuantan, Pahang, Malaysia \\ *Email: sharuzi@ump.edu.my \\ ${ }^{2}$ Manufacturing Focus Group, Faculty of Mechanical Engineering, Universiti Malaysia \\ Pahang, 26600 Pekan, Pahang, Malaysia \\ ${ }^{3}$ Grams Laboratory, Human Engineering Group, Faculty of Mechanical Engineering, \\ Universiti Malaysia Pahang, 26600 Pekan, Pahang, Malaysia
}

\begin{abstract}
The bioactive and biological affinity with bony tissue effect of hydroxyapatite (HA) is marked as the chosen material for implant applications. Uniting HA that has low mechanical properties that limit its application with higher mechanical property of metallic biomaterial SS 316L stainless steel (SS 316L) to form a composite has been a solution to produce acceptable mechanical properties for human implants. The SS316L/HA composite would have attributed vital to current implant materials, like a low Young's modulus, high compatibility, and bioinertness. This study investigated the mechanical and physical properties of the SS 316L/HA composite fabricated by metal injection moulding. The synthesis of HA was produced from calcium-phosphate. Meanwhile, polypropylene (PP), stearin acid (SA) and the primary binder, paraffin wax (PW) were used as a binder system. Different weights of HA (0 wt. \%, 5 wt. \%, 10 wt. $\%$ and $15 \mathrm{wt}$. \%) ratios to SS 316L/HA were prepared. All samples were sintered at $1350{ }^{\circ} \mathrm{C}$ for $2 \mathrm{~h}$ soaking time. The result showed that $10 \mathrm{wt}$. \% HA composite and above had higher porosity and low mechanical strength. However, SS 316L had a high relative density, which was $95.80 \%$, while $5 \mathrm{wt}$. \% HA relative density was $87.95 \%$ as compared to other additives of HA \% and hardness of $209.58 \%$ and $132.94 \%$, respectively. The increase in HA wt. \% content had routed the tensile strength and elongation of SS S316L/HA composite to decrease as it was brought closer to the human bone that had lower than tensile strength of $60 \mathrm{MPa}-130 \mathrm{MPa}$. Therefore, $5 \mathrm{wt}$ \% HA composite was found to be the most excellent powder ratio for SS 316L/HA composite in regard to mechanical and physical properties and to achieve the mechanical strength of the composite was necessary as the amount of HA content in the composite was smaller than 15 wt. \%.
\end{abstract}

Keywords: Biocompatible; metal; ceramic; composite; SS 316L/HA; Biomaterial. 


\section{INTRODUCTION}

Powder injection moulding (PIM) is a technology process that is based on injection moulding of metal powder. PIM process is moderately recognised as the development of processing industries. PIM is a net shaping process to fabricate a desired design and shape of a moulded part through mass production by using metal powder and it can produce intricate, small and precise compacts [1]. Powder metallurgy process is a well-established technique and viable alternative to investment machining and casting [2]. There are four necessary steps in PIM, which are mixing or kneading process, injection moulding, debinding and sintering process $[2,3]$. Each process represents different phase of sample: i) mixing process of metal powders and organic binders to prepare the feedstock, ii) injection moulding of feedstock to fabricate a green compact iii) debinding (solvent and thermal) process to form a brown compact and iv) sintering to be near full density by solid state diffusion, which is called as a sintered compact $[4,5]$.

Metals such as cobalt-chromium alloys (Co-Cr-Mo), titanium alloys (Ti-6Al-4 V) and stainless steel 316L (SS 316L) are well-known as metal alloys that are commonly used in dentistry and orthopaedics as implant materials.[6, 7]. There are many advantages of using these metals as biomaterials, for instance, excellent corrosion resistance, and outstanding mechanical properties [8]. The stainless steel 316L alloy is one of the medical-grade metals which are suitable devices for internal fixation $[9,10]$. Besides, $316 \mathrm{~L}$ is conventionally used as implant devices due to their characteristics, such as easy to fabricate, mechanical properties that are highly economical , i.e. good corrosion resistance, biocompatibility, high fatigue resistance and high tensile strength [11].

Hydroxyapatite (HA) with stoichiometric formula $\mathrm{Ca}_{10}\left(\mathrm{PO}_{4}\right) 6(\mathrm{OH})_{2}$ is the chief inorganic component of bones that are frequently used as a synthetic bone graph and scaffold for tissue engineering[12]. Basically HA is calcium phosphate ceramic in which its chemical, composition and structure are approximately identical with the human teeth and bone. It offers outstanding properties, such as being non-toxic, has bioaffinity with living tissues, high biocompatibility and osteoconductive [13]. Moreover, HA partakes low mechanical properties, for instance, low fracture toughness and brittleness, which give a boundary for its use in load-bearing applications [14]. Consequently, to improve the mechanical properties, metallic materials are used to fabricate tough metal-ceramic composites [15].

The SS $316 \mathrm{~L}$ and HA composites convey designate a promising biomaterial for replacement implant applications [3]. This present research is designed to fabricate SS S316L/HA composite to study its physical and mechanical properties and the microstructure behaviour of sintered SS 316L-HA composites. They can be obtained by the powder metallurgy process which can produce a product of mechanical strength, as well as excellent physical and chemical properties. Besides, this research explains the outcome of HA additive on composite mechanical and physical behaviours. 


\section{EXPERIMENTAL PROCEDURE}

\section{Material}

The SS 316L atomised gas was provided by Osprey Co. and was selected to be used as a metal powder to combine with bioceramic hydroxyapatite powder. Commercial hydroxyapatite powder was supplied by MSHC Industrial CO. LTD with a stoichiometric formula of $\mathrm{Ca}_{10}\left(\mathrm{PO}_{4}\right) 6(\mathrm{OH})_{2}$, and was used as material for the composite mechanical strength flexibility. Table 1 shows the characteristics of powders. The volume of powder loading used 60 vol\% with Binder's components shows detail in Table 2.

Table 1. Characterisation of metal and ceramic powders.

\begin{tabular}{cccccccc}
\hline Powder & $\begin{array}{c}\mathrm{D}_{50} \\
(\mu \mathrm{m})\end{array}$ & $\begin{array}{c}\mathrm{D}_{90} \\
(\mu \mathrm{m})\end{array}$ & $\begin{array}{c}\mathrm{D}_{10} \\
(\mu \mathrm{m})\end{array}$ & $\begin{array}{c}\mathrm{S}_{\mathrm{w}} \\
(\mu \mathrm{m})\end{array}$ & $\begin{array}{c}\text { Density } \\
\left(\mathrm{g} / \mathrm{cm}^{3}\right)\end{array}$ & Shape & $\begin{array}{c}\text { Melting } \\
\text { point }\left({ }^{\circ} \mathrm{C}\right)\end{array}$ \\
\hline SS 316L & 11.4 & 25.2 & 3.6 & 3.0 & 7.99 & Spherical & 1400 \\
HA & 70.26 & 137.46 & 29.61 & 3.84 & 3.06 & Spherical & 1300 \\
\hline
\end{tabular}

$\mathrm{D}_{50}$ is the mean particle size diameter for particle size distribution,

$\mathrm{D}_{90}$ and $\mathrm{D}_{10}$ indicate the distribution at $90 \%$ and $10 \%$ (cumulative) for size distribution curve, $\mathrm{S}_{\mathrm{w}}$ (slope parameter distribution $=2.56 / \log \left(\mathrm{D}_{90} / \mathrm{D}_{10}\right)$

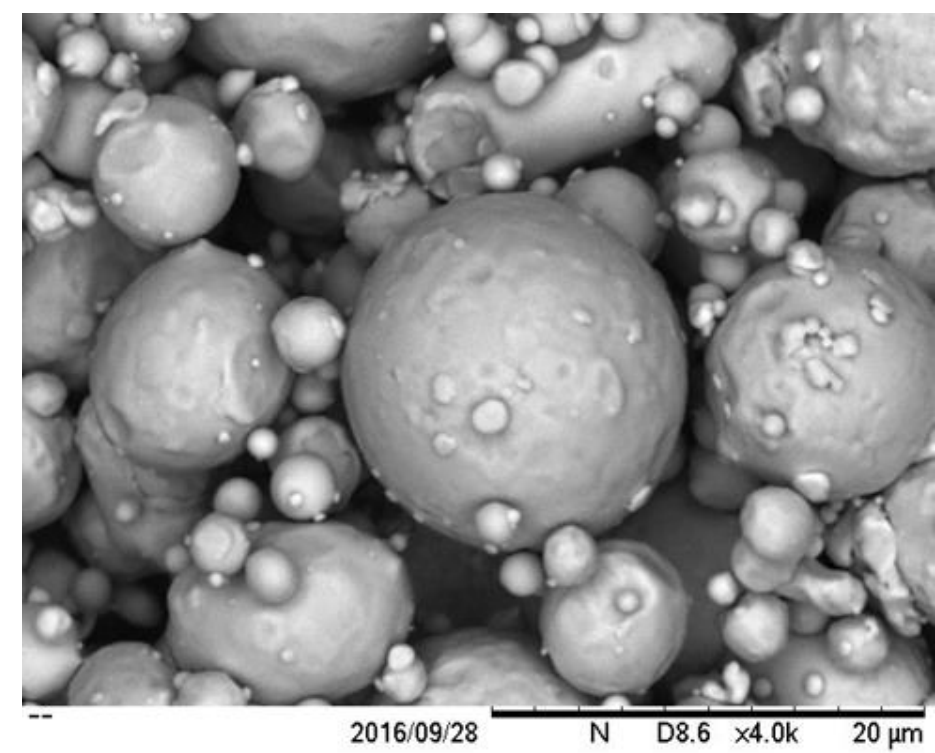

Figure 1. SEM image of SS 316L alloy powder. 


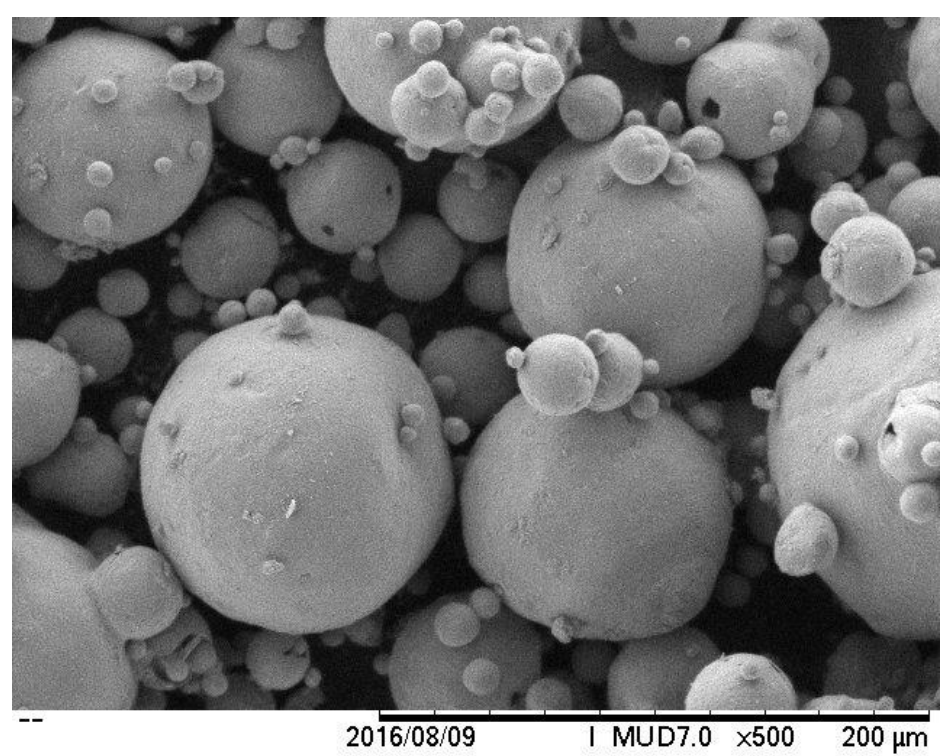

Figure 2. SEM image of hydroxyapatite powder.

Table 2. Binder characterisation.

\begin{tabular}{ccccc}
\hline Binder & $\begin{array}{c}\text { Chemical } \\
\text { structure }\end{array}$ & Density $\left(\mathrm{g} / \mathrm{cm}^{3}\right)$ & $\begin{array}{c}\text { Melting } \\
\text { temperature }\left({ }^{\circ} \mathrm{C}\right)\end{array}$ & $\begin{array}{c}\text { Decomposition } \\
\text { temperature }\left({ }^{\circ} \mathrm{C}\right)\end{array}$ \\
\hline $\mathrm{PW}$ & $\mathrm{C}_{31} \mathrm{H}_{64}$ & 0.91 & $47-65$ & $200-400$ \\
$\mathrm{PP}$ & $\left(\mathrm{C}_{3} \mathrm{H}_{6}\right) \mathrm{n}$ & 0.90 & $>95$ & $328-410$ \\
$\mathrm{SA}$ & $\mathrm{C}_{18} \mathrm{H}_{36} \mathrm{O}_{2}$ & 0.94 & 69.4 & $180-380$ \\
\hline
\end{tabular}

\section{Feedstock Preparation, Mixing and Injection Moulding Process}

Homogenisation of the SS 316L and HA powders was performed in a Portable V-Blender at a maximum rotational speed of $26 \mathrm{rpm}$. These powders were mixed in the V-Blender for 120 min. Then, the powders were mixed with binders to prepare the feedstock by using the double-planetary mixer at $150{ }^{\circ} \mathrm{C}$ and a rotational speed of $70 \mathrm{rpm}$ for $90 \mathrm{~min}$. The NISSEI Model NS20-2A injection moulding machine was utilised to fabricate the tensile-shaped compacts (ASTM E8). The injection moulding process successfully fabricated the green compacts at $150^{\circ} \mathrm{C}$. Based on observation, no defect was detected on the green compacts.

Table 3. The binder system for SS S316L/HA composite.

\begin{tabular}{cc}
\hline Binder Components & Composition (\%) \\
\hline Paraffin wax (PW) & 70 \\
Polypropylene (PP) & 25 \\
Stearic acid (SA) & 5 \\
\hline
\end{tabular}




\section{Debinding and Sintering Process}

Debinding process was conducted in two phases, which were solvent debinding and thermal debinding. Wicking technique was applied for solvent debinding by using fine $\mathrm{Al} 2 \mathrm{O} 3$ powders. Compacts were placed in a desiccator with vaporised $40 \mathrm{~mL}$ n-heptane at $60{ }^{\circ} \mathrm{C}$ for $4 \mathrm{~h} \mathrm{[16]}$. At this stage paraffin wax, as the primary binder, was removed from the green compact. The second stage of debinding was thermal debinding. Thermal debinding was done by using a furnace of $500{ }^{\circ} \mathrm{C}$ temperature with soaking time of 1 hand heating rate of 5 ${ }^{\circ} \mathrm{C} /$ min. Next, the compact was sintered at $1,350{ }^{\circ} \mathrm{C}$ with soaking time of $3 \mathrm{~h}$ and at $10^{\circ} \mathrm{C}$ $/ \mathrm{min}$ heating rate. In this experiment, thermal debinding and sintering were run in a tube furnace with argon atmosphere condition of $1 \mathrm{~mL} / \mathrm{min}$ flow rate.

\section{RESULT AND DISCUSSION}

\section{Physical Properties}

Figure 3 shows the tensile-shaped green and sintered compacts of SS316L/HA by using NISSEI Model NS20-2A injection moulding machine.

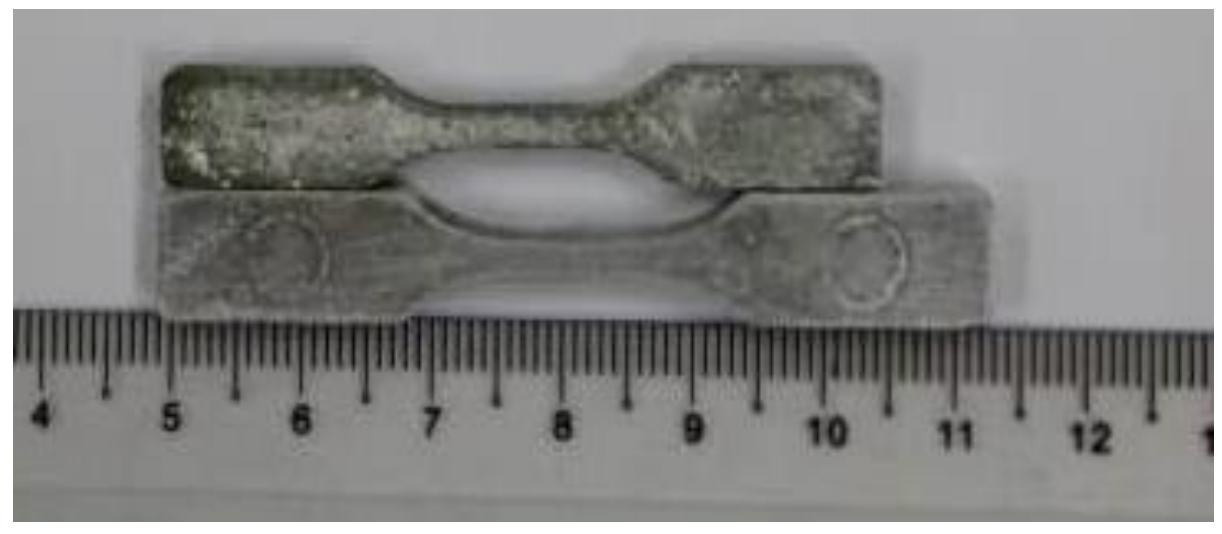

Figure 3. SS316L/HA (15 wt. \% HA) tensile-shaped compact without defects.

Figure 4 shows the experimental results of relative density. Meanwhile Figure 5 shows the microstructure of solid SS 316L/HA with compact porosity that is dependent on their amount of hydroxyapatite present in the powder mixtures. Based on the investigation results, it can be resolved that the relative density of SS 316L/HA composite sintered compact was lower than relative density of SS 316L sintered compact. The amount of HA additive in the powder mixtures affected the density, while the open and total porosity increased. It was apparent that the sintered compact with the highest content of HA presented the lowest density and higher porosity. 


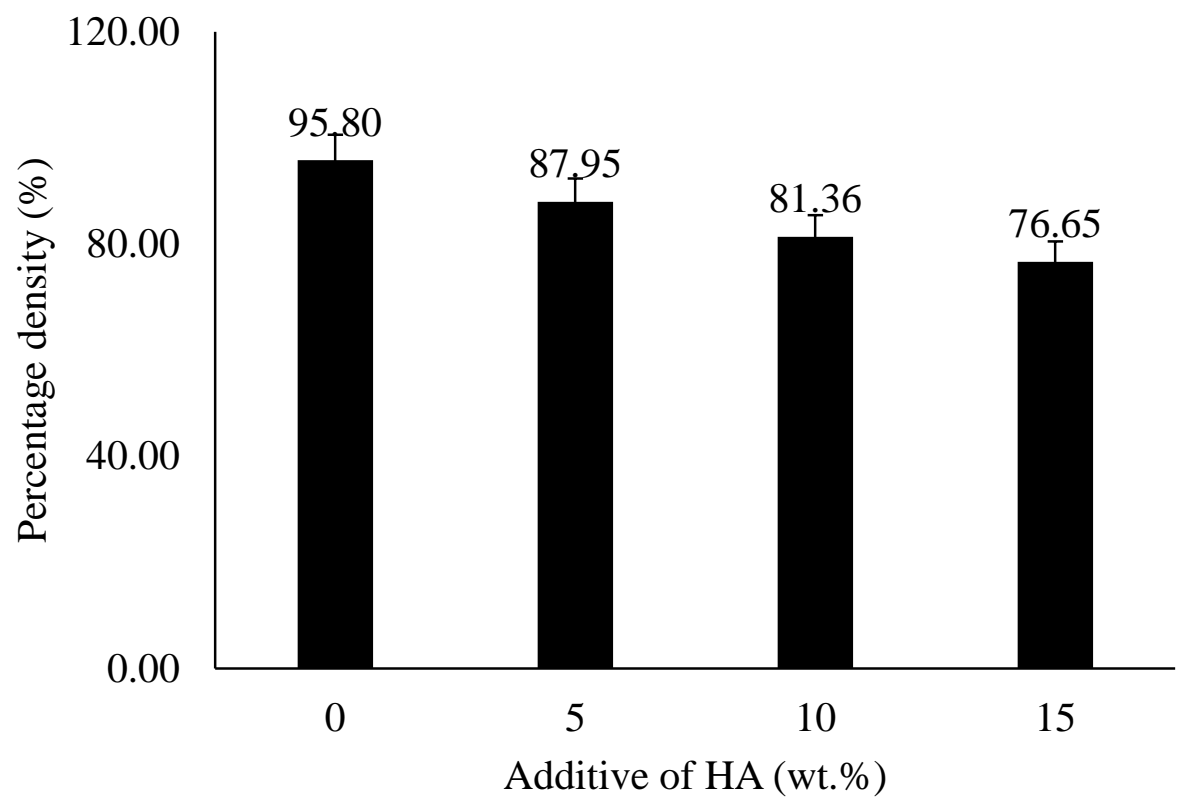

Figure 4. The influence of HA additive on SS 316L/HA sintered composite density.

(a)

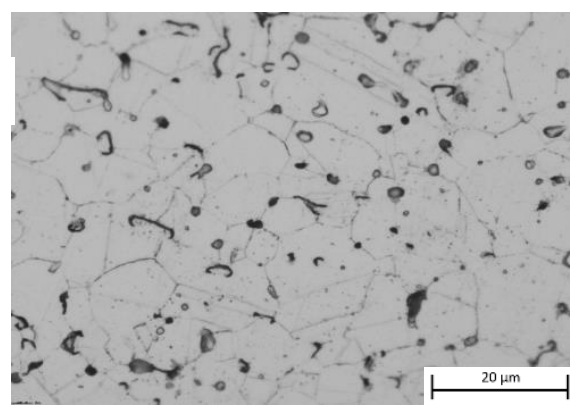

(c)

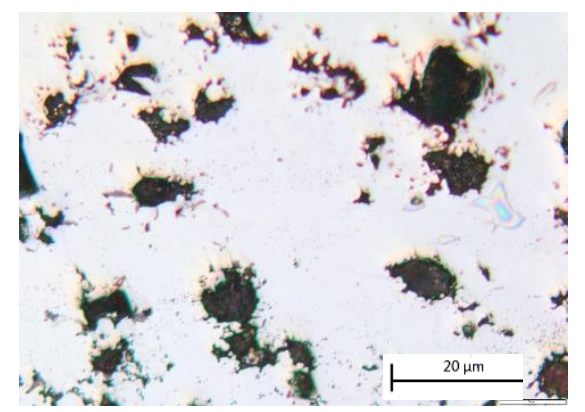

(b)

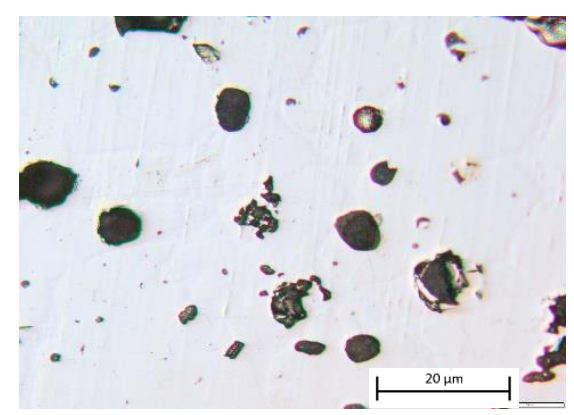

(d)

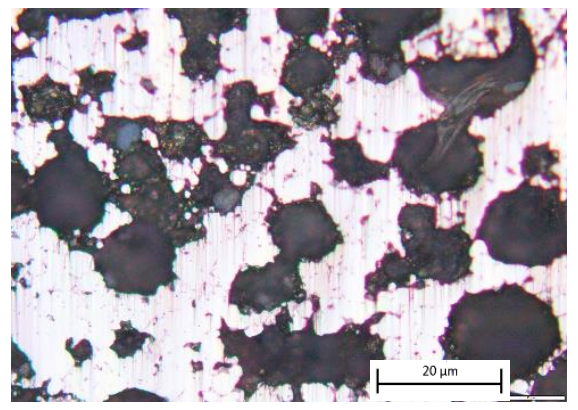

Figure 5. Microstructure images: (a) sintered SS 316L, (b) sintered SS 316L/ 5HA wt.\%, (c) sintered SS 316L/10 HA wt.\%, (d) sintered SS 316L/15 HA wt.\%. 
The lowest amount of HA additive of 5 wt.\% showed the highest relative density, which was $87.95 \%$ as compared to $10 \mathrm{wt} . \%$ and $15 \mathrm{wt} . \%$ HA additives. This decrease may have a relation with the reduction of ductility and compressibility of the biocomposites [17]. The ductility of SS 316L was higher than HA as it showed a lower amount of SS 316L in the mixture will lower relative density obtained. Sintered SS 316L/ 5 wt. \% HA composite showed the best physical properties. These outcomes agreed to the results that were originated by Younesi et al. [17] who investigated the tribological properties and physical behaviour on effects of HA additive of nickel free stainless steels [17]. Next, the sintered compact SS 316L/HA showed obvious pores as Figure 6 shows the graph of porosity $\%$ on different wt.\% HA with Image J. The graph trend clearly shows that the porosity \% increases with increased HA content in biocomposite. The outward values of porosity reached to $62 \%$ from $4.1 \%$.

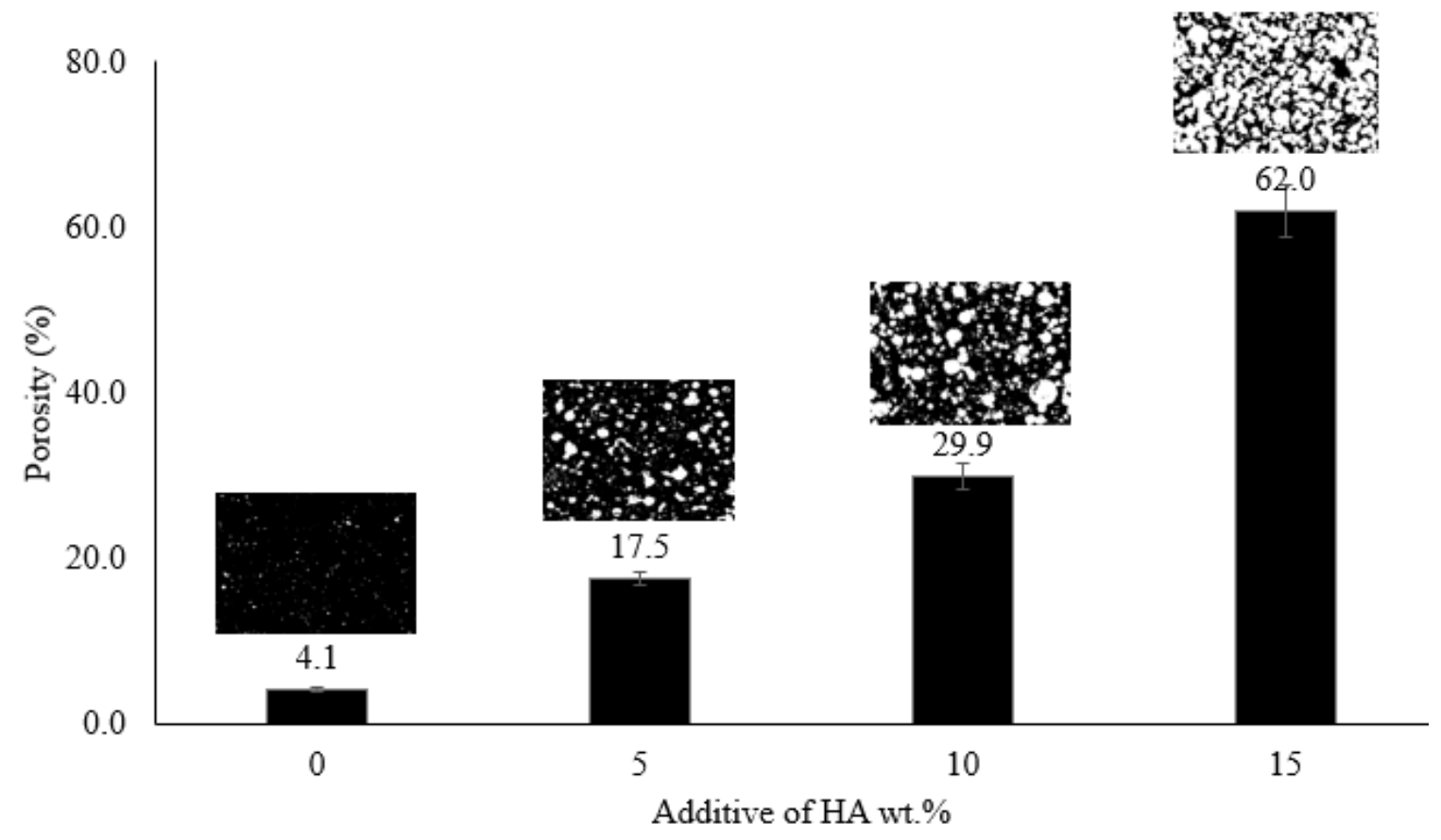

Figure 6. The influence of HA additive on sintered composite porosity.

The dimensional shrinkage of the green and sintered compacts was measured from its dimensional changes. The linear shrinkage of many MIM compacts are varied between $10 \%$ to $20 \%$ [18]. The shrinkage recorded in this work was in the range of $6.7 \%$ to $13.3 \%$. As shown in Figure 7, the highest shrinkage resulted from sintered compact with $13.3 \%$ on 5 wt. $\%$. HA condition. Meanwhile, additive of 15 wt. $\%$ of HA showed the lowest percentage of shrinkage. It can be concluded that the amount of shrinkage percentage gradually decreased with increase in the HA amount. Besides, higher content of HA was not affected by heat in the sintering process, which likened to SS 316L metal that enlarge at high temperature [14]. 


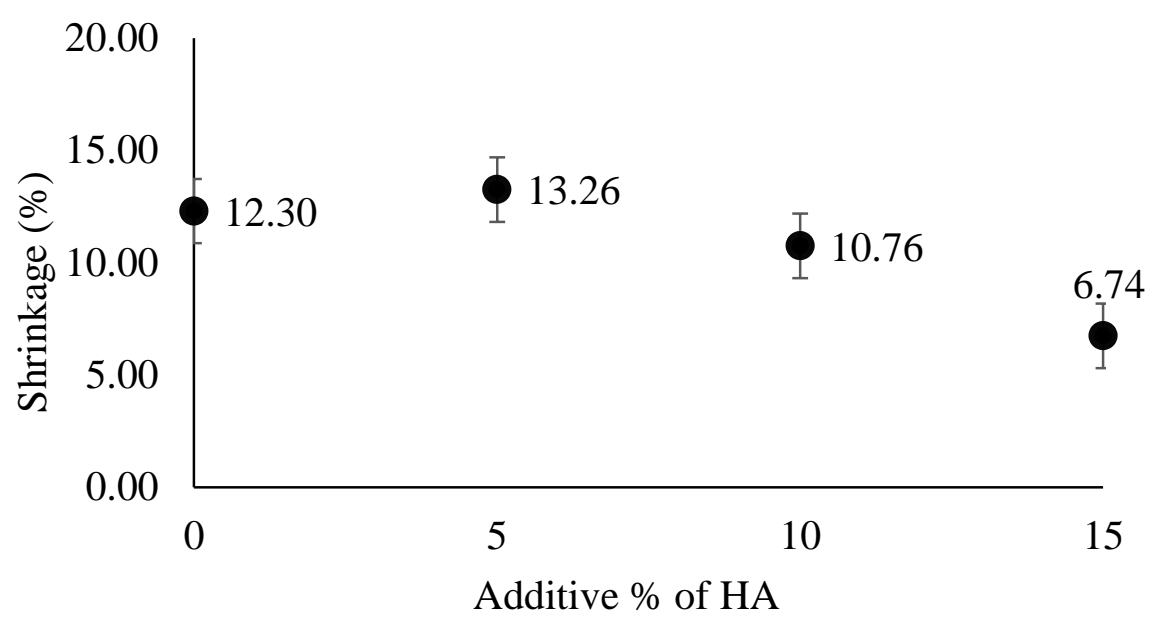

Figure 7. The influence of HA additive on shrinkage properties.

\section{Mechanical Properties}

\section{Tensile Properties}

Figure 8 shows the trends of tensile stress-strain for SS 316L/HA composite with different HA percentage contents. From these graphs it clearly shows that addition of $5 \mathrm{wt}$ \% HA will give the highest ultimate tensile stress (UTS).

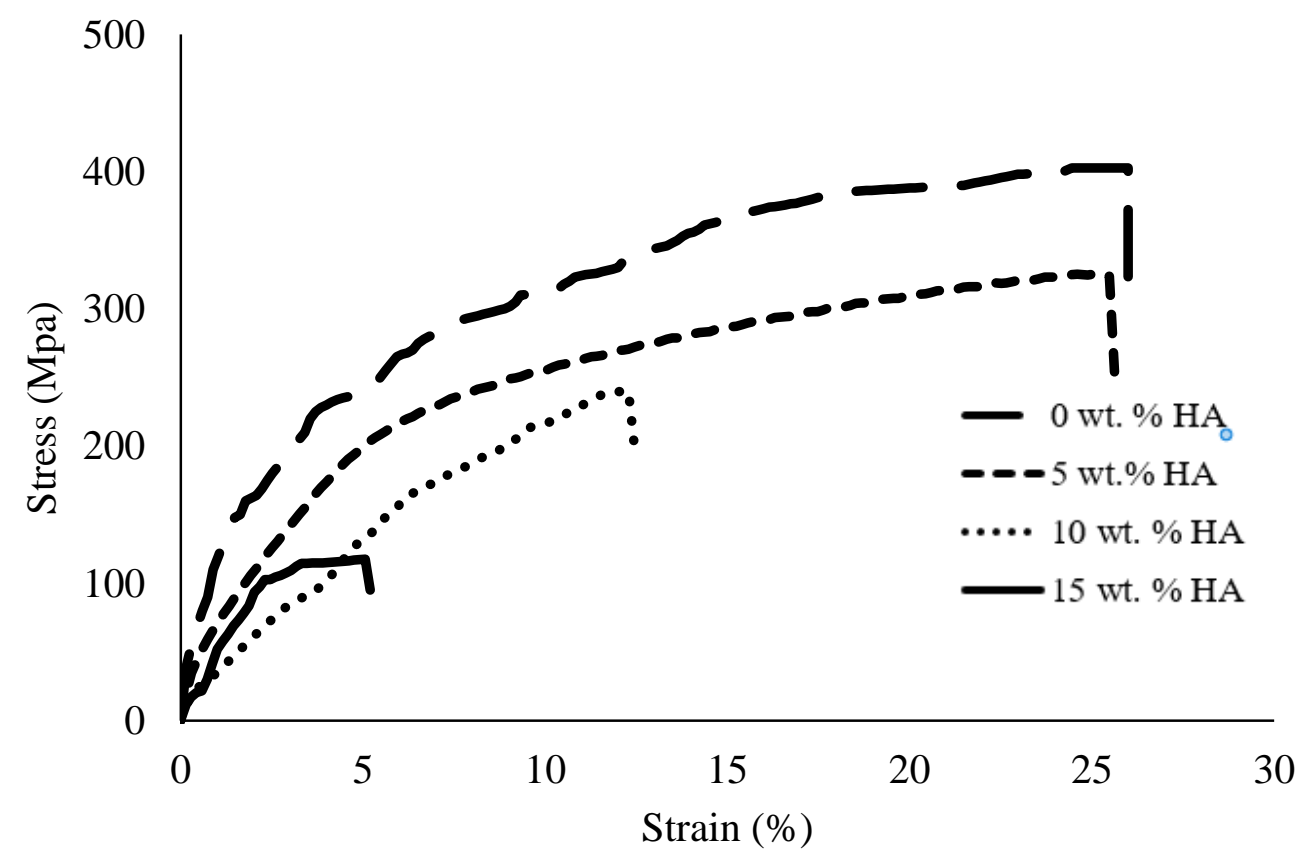

Figure 8. Stress-strain curve for SS 316L/HA biocomposite. 


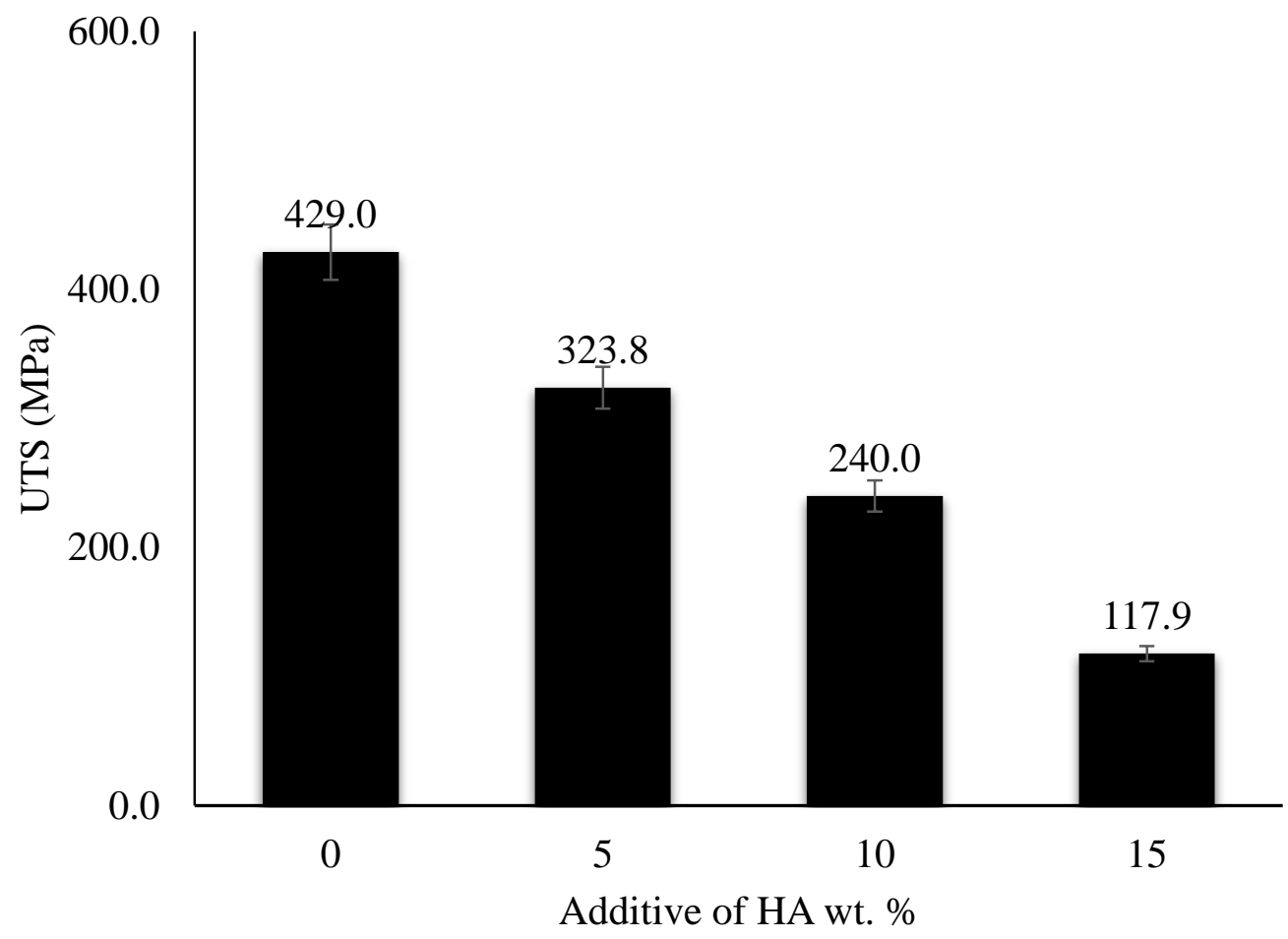

Figure 9. Ultimate tensile strength of SS 316L/HA biocomposite.

It can be renowned from Figure 9 that the tensile strength of the biocomposite sintered compact decreases as the content of HA increases. The biocomposite content of $5 \mathrm{wt}$. \% HA showed the closest value to the pure SS 316L, 323.8 and 429.0 MPa, respectively. It showed a lower strength with $10 \mathrm{wt}$. \% and $15 \mathrm{wt} . \% \mathrm{HA}$ contents of biocomposite. It can be concluded that with an increase in the content of HA in biocomposite, it showed a decrease in tensile strength, which nearly value with tensile strength of bone (human cortical bone), 60-130 MPa [19].

The microstructures of different sintered compacts obviously showed perceived high strength at lower amounts of HA ceramic powder on sintered compacts. The micro-voids or porosity appearances were due to interparticle spaces between 316 and HA detected as the utmost factor which affected the compact tensile strengths. Besides, the tensile strength of sintered compacts was affected by density. The higher value of density on sintered compact gave a stronger interparticle bonding as it avoided crack propagation and provided higher tensile strength [18]. 


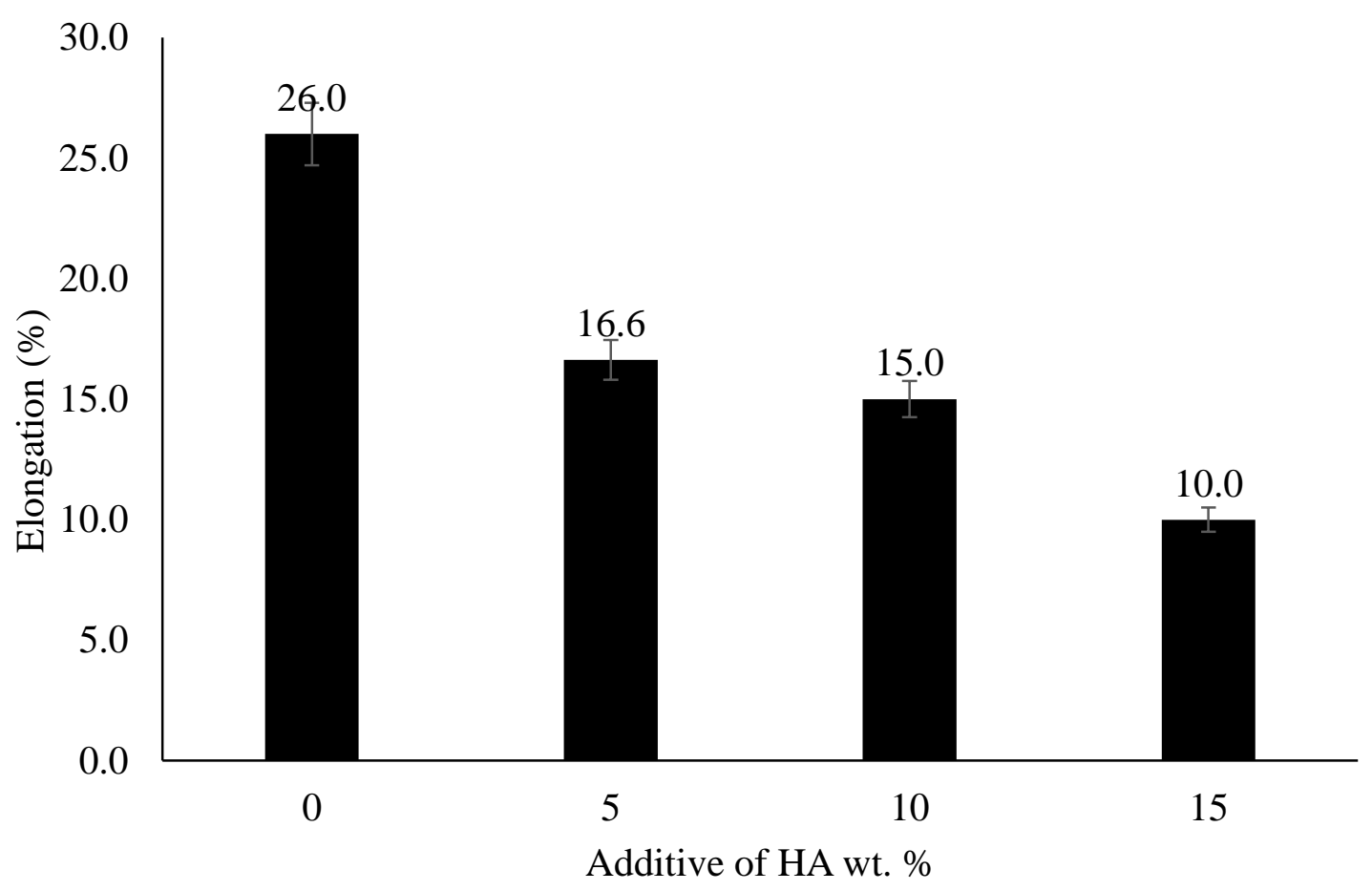

Figure 10: Elongation for SS 316L/HA biocomposite

Figure 10 presents the elongation result from the tensile test for sintered compact. Biocomposite of $5 \mathrm{wt}$. \% HA showed a higher elongation result of $16.6 \%$ as compared to 10 wt. $\%$ and 15 wt. \% powder ratio, which were $15.0 \%$ and $10.0 \%$, respectively. Pure SS 316L sintered compact showed the highest elongation, which was $26.0 \%$. From the graph, it can be said that the additive of HA ceramic in mixture gave a significant elongation result, whereby the elongation decreased with increased HA ceramic contents. It showed that at lower content of HA wt. \% in sintered compact, the elongation tended to be a bit lower. The highest amount of HA, which was 316L/15 wt. \% HA, recorded the lowest elongation percentage (10\%). Meanwhile, at high HA content, the elongation of sintered compacts showed lower intensity and ductility. This was possibly associated with the presence of pores and cracks that occurred from the aggregation of ceramic brittle composition [19].

\section{Hardness properties}

Figure 11 presents the Vicker's hardness of biocomposite as a function of HA ceramic content (wt. \%). It is noted that the graph shows the hardness result of all different HA wt. \% content is augmented with HA content. Comparable trends were stated in previous study [20]. This was owed to the increase in percentage of HA ceramic with lower hardness in composite that caused the composite hardness to decrease. The maximum hardness value of SS 316L/HA composite was found in composite with 0 wt. \% HA, which was $209.58 \mathrm{Hv}$, followed by $5 \mathrm{wt} . \% 10 \mathrm{wt} . \%$ of HA and pure SS 316L without HA content, $132.94 \mathrm{Hv}, 89.82$ $\mathrm{Hv}$ and $29.82 \mathrm{Hv}$, respectively. The enhancement of hardness was comeuppance with the combination of hard HA particles [20]. In addition, 316L/HA composite microhardness rallies with increase in HA content. 


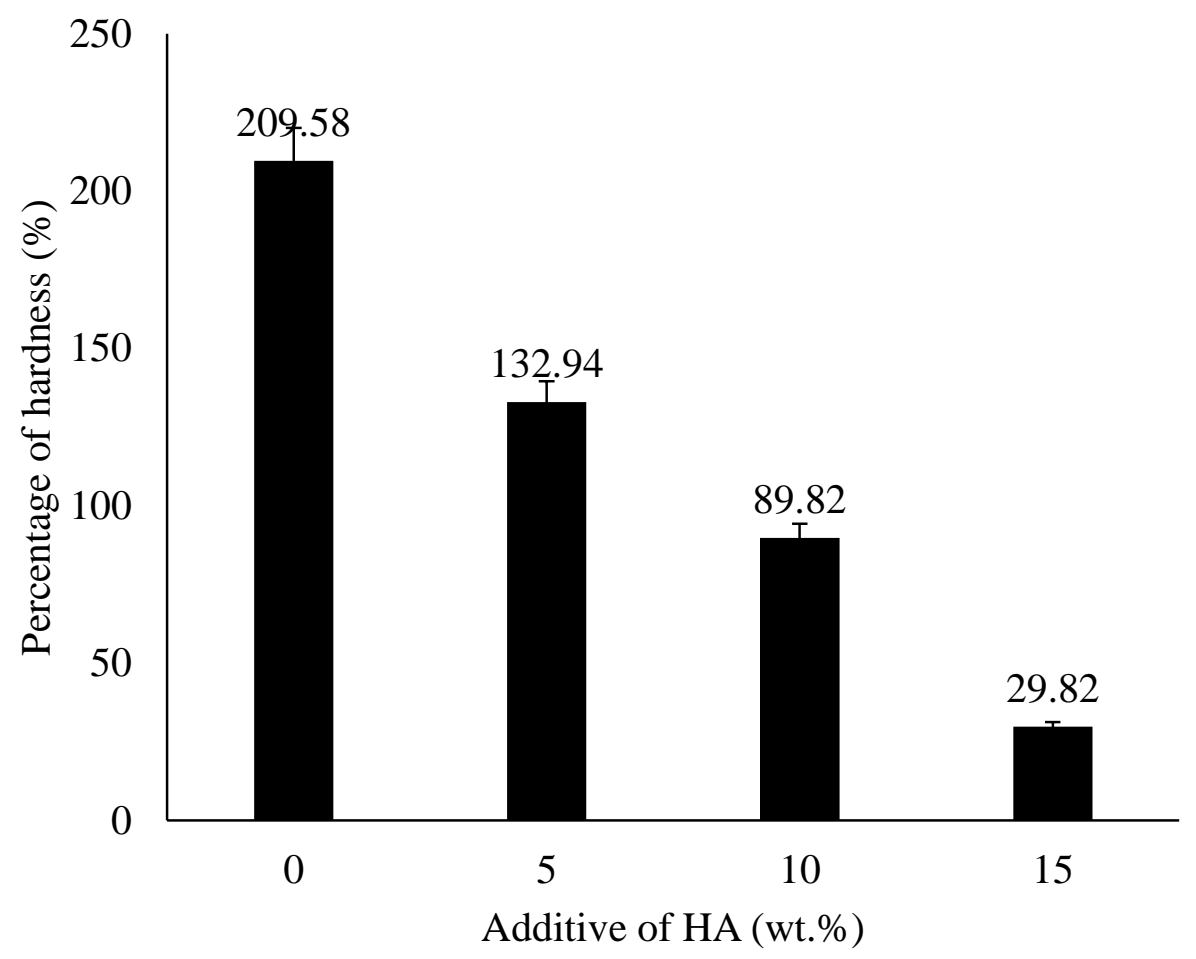

Figure 11. Vickers hardness variation functions of HA weight percentage in SS 316L/HA composite.

\section{CONCLUSION}

From the above results, the study concludes the following;

1) The amount of hydroxyapatite ceramic in the mixture of powders increases up to 15 wt.\%, sintered relative density and shrinkage percentage of SS 316L/HA composite decrease, while the open and total porosity increased. The additive of $5 \mathrm{wt}$ \% HA in SS 316L/HA sintered composite obtained the best physical properties which was at $87.95 \%$ relative density.

2) Hydroxyapatite additive chiefs to amend microstructure of sintered composite and modify the sintering behaviour since the content of HA is not affected by heat in the sintering process, which likened to SS 316L metal that enlarges in high temperature. As for the next study, the result will be enhanced by reducing the sintering temperature to accomplish the primary goal in powder metallurgy method.

3) From mechanical testing, the increase of HA additive in sintered compact routed the decrease in tensile strength and hardness. Composite with 5wt. \% HA showed the most excellent physical properties. However, the tensile strength of $323.8 \mathrm{MPa}$ surpassed the human bone strength, leading to the stress-shielding phenomena. Meanwhile, the composite of SS 316L/10wt.\% HA is closer to human bone strength with $240 \mathrm{MPa}$, and tensile strength of $15 \mathrm{wt} . \%$ of HA composite additive is in the range of human bone strength. The result achieved was seemed as an improvement in this 
research, in which the mechanical strength was closer to human bone properties. This combination of excellent properties can be applied in human load-bearing applications. The results showed that the composites in range of between $5 \mathrm{wt} . \%$ and $10 \mathrm{wt} . \%$ gave the best mechanical as the strength was closer to the human bone limit and high physical properties. Envisioned for future research, to maintain and achieve the strength of mechanical properties of SS 316L/HA biocomposite will require an amount of HA content in the composite which are below than 15 wt. \%. Besides, further study on corrosion behaviour can be done to investigate the biocompatibility of sintered compact.

\section{ACKNOWLEDGEMENTS}

Universiti Malaysia Pahang has given a complete supported in resources and facilities for this study. The authors would like to acknowledge the provision of the internal grant through Universiti Malaysia Pahang PGRS 180379, RDU 160307, RDU 160387 and the sustenance of Research Acculturation Collaborative Effort (RACE) supported by the Ministry of Higher Education, Malaysia RDU151314.

\section{REFERENCES}

[1] Ahn S, Park SJ, Lee S, Atre SV, German RM. Effect of powders and binders on material properties and molding parameters in iron and stainless steel powder injection molding process. Powder Technology. 2009;193(2):162-169.

[2] Hamidi MFFA et al. A review of biocompatible metal injection moulding process parameters for biomedical applications. Materials Science and Engineering: C. 2017;78:1263-1276.

[3] Ibrahim MHI, Mustafa N, Mohd AA, Asmawi R. Mechanical properties of SS316L and natural hydroxyapatite composite in metal injection molding. 2015.

[4] Hamidi $\mathrm{M}$ et al. A review of biocompatible metal injection moulding process parameters for biomedical applications. Materials Science and Engineering: C. 2017;78:1263-1276.

[5] Farhan MF, Hamidi A, Harun WSW, Faiz A, Abu Bakar S. Effect of binders on physical and mechanical properties of stainless steel 316L alloy fabricated by metal injection moulding process. 2016.

[6] Azem FA, Cakir A. Synthesis of HAP coating on galvanostatically treated stainless steel substrates by sol-gel method. Journal of sol-gel science and technology. 2009;51(2):190-197.

[7] Andrade MC, Filgueiras MRT, Ogasawara T. Hydrothermal nucleation of hydroxyapatite on titanium surface. Journal of the European Ceramic Society. 2002;22(4):505-510.

[8] Nayak CV, Ramesh M, Desai V, Samanta SK. Fabrication of stainless steel based composite by metal injection moulding. Materials Today: Proceedings. 2018;5(2):6805-6814. 
[9] Ji C, Loh N, Khor K, Tor S. Sintering study of 316L stainless steel metal injection molding parts using Taguchi method: final density. Materials Science and Engineering: A. 2001;311(1-2):74-82.

[10] Salleh F, Sulong A, Muhamad N, Mohamed I, Mas'ood N, Ukwueze B, " Co-powder injection moulding (Co-PIM) processing of titanium alloy (Ti-6Al-4V) and Hydroxyapatite (HA). Procedia engineering. 2017;184:334-343.

[11] Hao L, Lawrence J, Phua Y, Chian K, Lim G, Zheng H. Enhanced human osteoblast cell adhesion and proliferation on 316 LS stainless steel by means of CO2 laser surface treatment. Journal of Biomedical Materials Research Part B: Applied Biomaterials: An Official Journal of The Society for Biomaterials, The Japanese Society for Biomaterials, and The Australian Society for Biomaterials and the Korean Society for Biomaterials. 2005;73(1):148-156.

[12] Ong JL, Chan DC. Hydroxyapatite and their use as coatings in dental implants: A review. Critical Reviews ${ }^{\mathrm{TM}}$ in Biomedical Engineering. 2000;28(5-6).

[13] Szewczyk-Nykiel A, Nykiel M. Study of hydroxyapatite behaviour during sintering of 316L steel. Archives of Foundry Engineering. 2010;10:235-40.

[14] Oshkour AA, Pramanik A, Mehrali M, Yau YH, Tarlochan F, Osman NAA. Mechanical and physical behavior of newly developed functionally graded materials and composites of stainless steel 316L with calcium silicate and hydroxyapatite. Journal of the Mechanical Behavior of Biomedical Materials. 2015;49:321-331.

[15] Lalande J, Scheppokat S, Janssen R, Claussen N. Toughening of alumina/zirconia ceramic composites with silver particles. Journal of the European Ceramic Society. 2002;22(13):2165-2171.

[16] Hamidi M, Harun WSW, Khalil N, Ghani S, Azir M. Study of solvent debinding parameters for metal injection moulded 316L stainless steel. IOP Conference Series: Materials Science and Engineering. 2017;257(1):012035.

[17] Younesi M, Bahrololoom M, Fooladfar H. Development of wear resistant NFSS-HA novel biocomposites and study of their tribological properties for orthopaedic applications. Journal of the Mechanical Behavior of Biomedical Materials. 2010;3(2):178-188.

[18] Abdulah et al. Innovative metal injection molding (MIM) method for producing CoCrMo alloy metallic prosthesis for orthopedic applications. Advanced Materials Research. 2014;879.

[19] Zheng Z, Wang L, Jia M, Cheng L, Yan B. Microstructure and mechanical properties of stainless steel/calcium silicate composites manufactured by selective laser melting. Materials Science and Engineering: C. 2017;71:1099-1105.

[20] Xiong et al. Characterization of biomedical hydroxyapatite/magnesium composites prepared by powder metallurgy assisted with microwave sintering. Current Applied Physics. 2016;16(8):830-836. 